\title{
273 APPLICATION OF PHARMACOKINETIC- PHARMACODYNAMIC MODELING TO SELECT THE OPTIMAL DOSE OF ALX148, A CD47 BLOCKER
}

Oleg Demin*, Elena Vasileva. ISyBio, Moscow, Russian Federation

Background ALX148 is a fusion protein comprised of a highaffinity CD47 blocker linked to an inactive immunoglobulin Fc region. Optimal doses selection is increasingly important in clinical setup and can be guided by an assessment of target receptor occupancy (RO) and pharmacodynamics (PD) effect in the site of action. However, direct measurement of RO and $\mathrm{PD}$ effect in the tumor tissue is challenging. A mechanistic pharmacokinetic (PK)-PD model was developed to predict CD47 occupancy and PD effect in tumor tissues for ALX148.

Methods The developed semi-mechanistic PK/RO/PD model describes the PK of ALX148 and its distribution to non-Hodgkin lymphoma tumor tissues (lymph nodes, spleen, and bone marrow). The model includes non-linear clearance of ALX148 due to target CD47 receptor binding and further internalization of the complex. CD47 RO was described on red blood cells and tumor cells taking into account the number of cells and CD47 expression (molecules per cell). Parameters were fitted against clinical PK and in vitro data. In vitro data on stimulation of phagocytosis by ALX148 in the presence of antibodies inducing antibody-dependent cellular phagocytosis (ADCP) was used to estimate the RO-PD relationship. Clinical data on RO in the periphery was used for model validation.

Results The model successfully described dose-dependence ALX148 clinical PK and RO data. Predicted trough median CD47 occupancy in the spleen, lymph nodes, and bone marrow during the treatment with $10 \mathrm{mg} / \mathrm{kg}$ QW ALX148 was 98\% (95\% confidence bands: 95\%-99\%), whereas $30 \mathrm{mg} / \mathrm{kg}$ Q2W resulted in 99\% CD47 occupancy (95\% confidence bands: 98\%-99\%). ADCP of cancer cells was predicted to be increased by $\sim 1.8$ times during the treatment with both regimens of ALX148: $10 \mathrm{mg} / \mathrm{kg}$ QW and $30 \mathrm{mg} / \mathrm{kg}$ Q2W. Dose 3 $\mathrm{mg} / \mathrm{kg}$ resulted in the lower induction of ADCP than $10 \mathrm{mg} /$ kg: 1.6 vs 1.8 ( $\mathrm{p}$-value $<0.001$ ).

Conclusions The model was successfully calibrated and validated against both in vitro and clinical data on ALX148. It was predicted that $10 \mathrm{mg} / \mathrm{kg} \mathrm{QW}$ is an optimal dose of ALX148 to occupy more than 90\% of CD47 in the tumor tissues to achieve maximal induction of phagocytosis caused by ADCP stimulating antibodies such as rituximab. This approach can be applied for the optimal dose selection of other anti-CD47 agents taking into account their specific features as binding properties, size, etc.

http://dx.doi.org/10.1136/jitc-2021-SITC2021.273 